\title{
Artificial grammar learning in Williams syndrome and in typical development: the role of rules, familiarity and prosodic cues
}

Article

Accepted Version

Stojanovik, V., Zimmerer, V., Setter, J., Hudson, K., PoyrazBilgin, I. and Saddy, D. (2018) Artificial grammar learning in Williams syndrome and in typical development: the role of rules, familiarity and prosodic cues. Applied Psycholinguistics, 39 (2). pp. 327-353. ISSN 1469-1817 doi:

https://doi.org/10.1017/S0142716417000212 Available at https://centaur.reading.ac.uk/70475/

It is advisable to refer to the publisher's version if you intend to cite from the work. See Guidance on citing.

To link to this article DOI: http://dx.doi.org/10.1017/S0142716417000212

Publisher: Cambridge University Press

All outputs in CentAUR are protected by Intellectual Property Rights law, including copyright law. Copyright and IPR is retained by the creators or other copyright holders. Terms and conditions for use of this material are defined in the End User Agreement. 


\section{CentAUR}

Central Archive at the University of Reading

Reading's research outputs online 


\begin{abstract}
Artificial grammar learning (AGL) is an empirical paradigm which investigates basic patternand structural processing in different populations. It can inform how higher cognitive functions, such as language use, take place. Our study used AGL to assess how children with Williams syndrome (WS) $(n=16)$ extract patterns in structured sequences of synthetic speech, how they compare to typically developing (TD) children $(n=60)$, and how prosodic cues affect learning. The TD group was divided into: a group whose non-verbal abilities (NVMA) were within the range of the WS group, and a group whose chronological age (CA) was within the range of the WS group. TD children relied mainly on rule-based generalization when making judgements about sequence acceptability, whereas children with WS relied on familiarity with specific stimulus combinations. The TD participants whose NVMA were similar to the WS group, showed less evidence of relying on grammaticality than TD participants whose CA was similar to the WS group. In absence of prosodic cues, the children with WS did not demonstrate evidence of learning. Results suggest that, in WS children, the transition to rule-based processing in language does not keep pace with TD children and may be an indication of differences in neuro-cognitive mechanisms.
\end{abstract}

Keywords: Williams syndrome, prosody, language, artificial grammar

\title{
1. Introduction
}


Linguistic input in language acquisition is thought to consist of strings of words which conform to the grammatical patterns of the target language (Maratsos \& Chakley, 1980; Pinker, 1984; Wexler \& Culicover, 1980). Language processing involves the ability to parse these strings, detect regularities and generalise them onto new sequences. One way to determine the basic principles on which these processes take place is to observe them in artificial grammar learning (AGL) tasks. AGL (Reber, 1967) is an empirical paradigm which has contributed to research on the relationship between general information structure processing and language. AGL investigates how individuals parse combinations of stimuli, extract knowledge about their structure, and apply this knowledge to new combinations. AGL tasks have been used over the last 50 years to identify the representations acquired through learning, and to model language or syntax acquisition (Pothos, 2007). AGL can reveal processing biases underlying developmental profiles. The present study investigates how children and adolescents with WS extract patterns from structured sequences of AGL stimuli, how they compare to typically developing (TD) children, and how pattern extraction processes may change in TD children during maturation. Traditionally, auditory AGL tasks have been presented with no prosodic cues. However, natural language provides cues to language structure, such as prosody, which is particularly relevant for language acquisition. We therefore also investigated how prosodic cues affect learning.

\subsection{The Williams syndrome (WS) neuro-cognitive profile}

WS is a genetic disorder which occurs due to a micro-deletion on the long arm of chromosome 7q23 affecting the alleles of the elastin gene (Tassabehji et al., 1999). It is estimated to affect 1 in 20,000 to 25,000 live births (Greenberg, 1990), with the most recent epidemiological study suggesting an incidence rate of 1 in 7,500 live births (Strømme, Bjømstad, \& Ramstad, 2002). Individuals with WS typically display an uneven neuro- 
cognitive profile, with mild to severe learning difficulties, serious impairments in problem solving and deficits in spatial cognition, but relatively good social cognition, linguistic abilities and auditory rote memory (Mervis \& Klein-Tasman, 2000). Initial descriptions of the WS profile emphasised the discrepancy between superior language abilities, social overfriendliness and seemingly normal face-processing abilities, and impaired general cognitive abilities (Bellugi, Sabo, \& Vaid, 1988; Bellugi, Bihrle, Neville, Jernigan, \& Doherty, 1992; Bellugi, Wang, \& Jernigan, 1994; Bellugi, Lichtenberger, Mills, Galaburda, \& Korenberg, 1999).

There is growing evidence, however, to suggest that the overall linguistic performance in individuals with WS matches their nonverbal mental age in terms of morpho-syntactic skills, expressive and receptive vocabulary, expressive and receptive prosody (e.g., Brock, 2007; Stojanovik, Perkins \& Howard, 2004; Stojanovik, 2010; Stojanovik, 2012; Ypsilanti, Grouios, Alevriadou, \& Tsapkini, 2005). In addition, children with WS have been shown to perform not only similarly but also worse than mental age matched controls and/or children with Down syndrome (DS), on comprehension and production of wh-questions and understanding of passive sentences (Joffe \& Varlokosta, 2007). These studies challenge claims of superior language abilities in individuals WS as well as assumptions that their language develops independently of general cognitive processes.

As an alternative, it has been suggested that language acquisition in WS follows an atypical trajectory (Mervis \& John, 2012), and that, although individuals with WS may show similar behavioural outcomes on various tasks, they achieve these via different cognitivelevel and neural-level processes compared to neuro-typical individuals (Karmiloff-Smith \& Farran, 2012). For example, unlike typically developing (TD) children and those with DS, children with WS do not show referential pointing prior to the onset of referential language (Mervis, Robinson, Rowe, Becerra, \& Klein-Tasman., 2004). Despite missing this early 
precursor to language, they still achieve relatively good vocabulary scores, especially with concrete vocabulary which is more dependent on referential pointing (Mervis \& John, 2008). Similarly, an earlier study by Stevens and Karmiloff-Smith (1997) reported that individuals with WS used slightly different strategies when acquiring new words. Unlike TD children who use fast mapping and show mutual exclusivity, whole object and taxonomic constraints, individuals with WS appear to only use fast mapping and mutual exclusivity criteria. Yet, receptive vocabulary is a recognised strength in individuals with WS (Brock, 2007), which suggests that despite similar behaviour (equivalent vocabulary scores between TD and WS groups), individuals with WS may acquire new words in a different manner from TD children. More evidence comes from Nazzi, Paterson, and Karmiloff-Smith (2003) who showed that children with WS aged between 15 and 48 months were unable to segment words with a weak-strong stress pattern. Yet, the mean expressive vocabulary for the group was 83 words suggesting that, although an important precursor to language (speech segmentation) may not have been fully acquired, the children had acquired some language.

The view that seemingly similar behaviours may be grounded in different neural systems is supported by neuroimaging studies in domains other than language. For example, Grice et al. (2003), using event related potentials (ERPs), showed that, although individuals with WS manifested typical susceptibility to visual illusions, their neural activation was substantially different from activation in neuro-typical controls.

Underlying higher cognition in WS may be a dissociation between local (piecemeal or detailed focused) and global (holistic) processing. Individuals with WS have shown a local over a global processing bias (Bellugi, Lichtenberger, Jones, Lai \& St George, 2000; Farran, Jarrold \& Gathercole, 2003; Karmiloff-Smith et al., 2004). This is different from typical adults who process faces based on their global configuration rather than individual features (Young, Hellawell, \& Hay, 1987). A recent study by D’Souza, Booth, Connolly, Happé and 
Karmiloff-Smith (2015) demonstrated, in a series of tasks, that individuals with WS did not show a consistent local processing bias. In TD children, there is a shift, from global processing in early infancy to a local processing bias in early childhood to a more global processing bias becoming more dominant between the ages of 6 and 10 (Mondloch, Grand, \& Maurer, 2002; Poirel, Mallet, Houdé, \& Pineau, 2008). Neurophysiological evidence suggests that the shift from a local to a global processing bias may be related to a reduction of grey matter along the visual dorsal stream (Poirel et al., 2008). An fMRI study of individuals with WS showed that, on a global processing task, there was reduced activation of the dorsal stream pathway (Mobbs, et al., 2007).

Despite evidence that behavioural, cognitive and neural processes in WS may differ from the typical population, and seemingly similar behavioural responses may be the result of the involvement of different cognitive mechanisms (Karmiloff-Smith, 2012), the majority of studies investigating language in WS have so far focused on accuracy scores, which may not reveal how participants generally perceive and structure information. The evidence to date suggests that the linguistic differences between the WS and TD populations may result from differences in general cognitive abilities and that, although individuals with WS may show similar behavioural outcomes on various tasks to neuro-typical controls, the behaviour outcomes in WS may be grounded in different neuro-cognitive mechanisms. These investigations are crucial in order to fully understand the neuro-cognitive profile of WS and address how individuals with WS approach the task of language acquisition at a more fundamental level and what is the involvement of general cognitive mechanisms.

\subsection{Artificial grammar learning and the contribution of prosodic cues}

AGL is an empirical paradigm which has contributed to research on the relationship between general information structure processing and language. AGL experiments typically consist of a training phase and a test phase. During training, participants are presented with 
stimulus sequences which differ from one another, but share an underlying structure; they are generated by the same "grammar". In the test phase, new sequences are presented. Some are grammatical with regards to the target grammar, others are ungrammatical. Participants accept or reject test sequences based on whether they "fit" with the training sequences. Behavioural patterns indicate which aspects of the grammar were learned and generalised. Because experimenters can control the lexical-semantic nature of the stimuli, the sensory modality in which the stimuli are presented, and the structural complexity of the stimuli combinations, it is possible to investigate the relationship between specific processing (or learning) mechanisms and language. Importantly, the paradigm has been used to investigate different ways in which participants approach stimulus sequences (Pothos, 2007; Visser, Raijmakers, \& Pothos, 2009; Zimmerer, Cowell, \& Varley, 2011). AGL performance is related to a speaker's ability to predict language input based on the semantic and statistical context (Conway, Bauernschmidt, Huang, \& Pisoni, 2010). Typically developing sevenmonth-old infants are able to extract syntactic information from stimulus sequences only after a couple of minutes of exposure (Marcus, Vijayan, Rao, \& Vishton, 1999), and eight-monthold infants have access to the "powerful mechanisms for the computation of statistical properties of the language input" (Saffran, Aislin, \& Newport, 1996, p.1926).

AGL tasks engage left inferior areas in the brain, in particular Broca's area (Petersson, Forkstam, \& Ingvar, 2004; Petersson, Folia, \& Hagoort, 2012), and studies using AGL have contributed towards our understanding of language pathology in different clinical populations, such as for example people with aphasia (Christiansen, Kelly, Schillock, \& Greenfield, 2010; Dominey, Hoen, Blanc, \& Lelekov-Boissard, 2003; Zimmerer, Cowell, \& Varley, 2014; Zimmerer \& Varley, 2015), by providing evidence for an underlying impairment of general sequence structure processing systems. 
The first (and to our knowledge only) study to investigate AGL in WS was by Don, Schellenberg, Reber, Girolamo, and Wang (2003). Twenty-seven individuals with WS, spanning a wide age range (9-49), and 27 chronological age matched controls took part in two implicit learning tasks, one of which was an AGL task containing visually presented stimuli. Although the individuals with WS showed evidence of learning, the control group matched for chronological age outperformed the WS group in the AGL task. Differences in learning were related to between group differences in non-verbal intelligence and working memory: when either counting span and K-BIT Matrices scores were included as covariates, differences were not significant. By contrast, differences in vocabulary did not eliminate the between-group differences. This study suggests that information processing capacities in WS are largely on a par with their mental age.

AGL tasks (if presented auditorily) have traditionally been presented with no prosodic cues. However, natural language incorporates cues to language structure, such as prosody (Morgan, Meier \& Newport, 1987). Prosodic cues are particularly important in early child language acquisition. For example, newborn infants discriminate between languages on the basis of their rhythmic properties (Jusczyk, Cutler, \& Redanz 1993); at age 6 months, infants rely on prosodic cues to segment incoming speech into words (Jusczyk et al., 1993) as well as to acquire the syntactic rules of language (Hirsh-Pasek et al., 1987). The evidence is mixed with regard to what extent and whether children (aged 5 and above) make use of prosody in language processing. Beach, Katz and Skowronski (1996) show that 5-year old children use intonational or duration properties to disambiguate ambiguous phrases, but Snedeker and Trueswell (2001) present evidence that 5-year old children do not use prosody to disambiguate ambiguous sentences. Evidence from adults suggests that adult listeners do not necessarily rely on prosodic cues when other cues such as lexical or segmental cues are available in the input (Mattys, White, \& Melhorn, 2005). Individuals with WS have been 
reported to have expressive and receptive prosodic abilities in line with their language abilities (Stojanovik, Setter \& van Ewijk, 2007) which would suggest that they are able to use prosody in language processing. In addition, individuals with WS are very interested in music; some learn to sing and play musical instruments very successfully and have enhanced absolute pitch perception, which has led some to suggest that music is a preserved domain in WS (Lenhoff, 1998; Levitin \& Bellugi, 1998; Levitin et al., 2004). It has been postulated in theoretical models that there are certain commonalities between language and music, in that they share similar developmental mechanisms (McMullen \& Saffran, 2004; Trehub, 2003), and they share processing resources, especially those which are dedicated to the processing of structural relations which unfold over time (Patel, 2003). Elsabbagh, Cohen and KarmiloffSmith (2010) suggested that children with WS may be lacking the sensitivity to prosodic contour cues and may require a more extended period of exposure to linguistic input in order for them to discover language structure.

We present a novel AGL study which investigates differences between children with WS and TD controls, with a particular focus on whether participants from different groups extract different types of structural information from stimulus sequences. In particular, we aim to see how both groups make use of grammaticality, as determined by rules, and familiarity, as determined by the frequency of stimuli or stimulus combinations encountered during training, when accepting and rejecting sequences in the test phase. We further investigate each group's sensitivity to prosodic cues. We will also subdivide the TD group into a non-verbal ability matched TD group (matched to the WS group on non-verbal ability) and an age matched TD group (matched to the WS group on chronological age) so that we can further investigate the effect of chronological age on the children's use of grammaticality or familiarity in making the judgements, as well as their use of prosodic cues.

\section{Method}


AGL experiments are challenging to conduct on child populations because of demanding task instructions (judge whether new sequences are correct based on the training set). In infant populations, AGL tasks do not involve decisions, but the use of the habituation/headturn preference paradigm. However, head-turn preference data become unreliable as children become older and develop stronger executive control. Our design is novel and includes a narrative which serves to make the decision task more child-friendly and easier to understand. "Words" in the artificial language were mapped to aspects of events which were presented together with each sequence.

\subsection{Participants}

All participants were monolingual children aged between four and eighteen years of age. Nineteen participants with WS were originally recruited through the WS Foundation in the United Kingdom. These represented $70 \%$ of the total number of participants available in the South of England (a list of 27 participants aged between 6 and 16 from the South of England was provided by the WS Foundation), hence our sample is fairly representative of the WS population living in the South of England. Because the task manipulated prosody, in order to minimise any issues arising from regional variation, we recruited exclusively from the South of England. Other studies investigating prosodic aspects of language in children and adolescents with WS had similar sample sizes or smaller mainly due to the rarity of the syndrome and the relatively small numbers of participants available within a certain age band (e.g. Catterall et al., 2006; Martinez, Stojanovik, Setter \& Sotillo, 2012; Reilly, Klima \& Bellugi, 1990; Setter, Stojanovik, van Ewijk \& Moreland, 2008; Stojanovik, Setter \& van Ewijk, 2007; Stojanovik, 2010).

Diagnosis of WS in all participants had previously been confirmed by a clinician and a positive Fluorescence in Situ Hybridization (FISH) test to ensure deletion of the elastin gene, observed in $95 \%$ of those with WS (de Souza, Moretti-Ferreira, \& Rugolo, 2007). Three 
participants had to be excluded from the analyses because they showed a strong response bias (100\% rejection or $100 \%$ acceptance of test sequences) during the AGL task, or did not complete the task. The analysis is therefore based on 16 participants with WS (Mean age $=9$ years 7 months, range between 6 years 0 months - 18 years 5 months; 7 males, 9 females). There were eight participants in the prosody (WSP) and eight in the no prosody condition (WSNP).

Sixty three typically developing children were recruited through the Child Development Research Group participant database at the University of Reading and from local and regional schools. Of these, three children were excluded from the analyses due to missing data, strong response bias, or failure to complete the task, hence analyses are based on data for 60 children (Mean age $=7$ years 5 month; range between 3 years 4 months and 12 years 1 month; 31 males, 29 females). Thirty three participated in the prosody condition (TDP), and 27 in the no prosody condition (TDNP). In addition to comparing the entire TD participant group with the group with WS, we split TD participants according to their Raven's Coloured Progressive Matrices (RCPM) scores with the aim of creating a subgroup that matches the children with WS in general cognitive ability. Because children with WS have general cognitive abilities which are lower than expected for their chronological age (Thomas, Purser, \& Van Herwegen, 2012), and the fact that general cognitive abilities may be related to children's ability to learn an artificial grammar (Don et al., 2003), the performance of the WS group on the AGL task was compared with that of TD children who have similar general cognitive abilities as measured by the RCPM. This allows for the pattern of performance of the WS group to be assessed as being commensurate to their general level of non-verbal ability, or to their CA, or as deviating from the patterns of performance of both control groups, and possibly not following a typical developmental trajectory (Farran, Jarrold \& Gathercole, 2003). RCPM was chosen because it has been shown that it is a valid means of 
matching TD children and those with intellectual disabilities on mental age in experimental studies (Goharpey, Tsoutsoulis \& Crewther, (2012). The reason raw scores are selected over standardised scores was that the latter are age-corrected. It would therefore not be possible to recruit TD children with matched standardised scores, as these participants would be considered severely delayed or impaired (3 SDs below the mean). Because the highest RCPM raw score in the WS was 21 , we used this value as a cut-off point. This created two groups: a non-verbal mental age (NVMA) group which did not differ from the WS group for NVMA and was subsequently younger, and a chronological age (CA) matched group which did not differ from the WS group on chronological age (subsequently older and with higher NVMA).

The study had received full ethical approval from the University of the University of Reading.

\subsection{Materials}

Standardised Tasks: Participants completed Raven's Coloured Progressive Matrices (RCPM; Raven, 2007) as a measure of fluid intelligence which is suitable for use in developmental disorder groups (e.g., Farran et al., 2003). The Word Structure subtest of the Clinical Evaluation of Language Fundamentals (CELF-4) or the Pre-School version, CELF-2 were used (Semel, Wiig, \& Secord, 2004; the choice of test depended on a participant's age) to assess expressive language ability. For 5 typically developing participants older than $8 ; 11$, the Formulated Sentences subtest was used as there is no Word Structures subtest for children between the ages of 9 and 16;11. Thus we also report percentage correct (rather than only raw scores) in order to make the results of the standardised language assessments comparable.

Table 1 shows participant group demographic information regarding chronological age and their raw scores for the RCPM and CELF percentage correct scores (as depending on the child's age either Word structures from the Pre-school -2 or School version of the CELF-4, or 
the Formulated sentences subtest for the CELF-4 were used). We report standardized RCPM scores for reference, but do not use these in analysis (see Table 1). We did not obtain RCPM scores from one child in the TD group. We included this child in the analysis of the full group, but excluded her from the subgroup analysis. We also were unable to obtain RCPM scores from two children in the WS group. Note that the results do not differ with the exclusion of these children.

\section{INSERT TABLE 1 AROUND HERE}

Table 2 shows the comparisons between the WS group and the TD groups. As evident from Table 2, when the WS group was compared to the TD group (pooled together), the TD children were significantly younger than the participants with WS and performed significantly better than the WS group on RCPM and CELF. The TD group, which was matched to the WS group on RCPM raw scores, were also significantly younger that the WS group and had significantly higher percentage correct scores on the CELF (Word Structures/Formulated sentences subtest). The unmatched TD group did not differ from the WS group on chronological age, but outperformed it on RCPM and the CELF (Table 2).

\section{INSERT TABLE 2 AROUND HERE}

\subsection{The Artificial Grammar Learning task}

We used auditory stimuli which were shown simultaneously with events on a computer screen. The grammar used in this task can be described as $\mathrm{A}(\mathrm{B}) \mathrm{C}$. It consisted of three word classes A, B and C. Each class was mapped to one aspect of an event which was presented on the screen, which was usually an animal. Class A referred to the object type appearing on screen. Class B referred to the size or color of the object. Class C referred to what happened to the object (e.g., it might spin or zoom in). The semantic mapping was made 
to support congruency between different types of information. Membership to each word class was marked by a distinct phonological onset and each item was disyllabic. Words of class A and B were CVCV(C). Class A words began with a liquid consonant followed by [a], then by a nasal consonant followed by $[\mathrm{a}],[\mathrm{p}]$ or $[\varepsilon]$ with an optional final consonant (for example 'rana' or 'lanel'). All class B words began with a voiceless alveolar fricative followed by $[\varepsilon]$ or $[\mathrm{u}]$ and then by any consonant followed by [i], [əซ] or [u] with an optional final consonant (for example: 'subi'). Words of class $\mathrm{C}$ were $\mathrm{CV}(\mathrm{C}) \mathrm{CVC}$, starting with a voiced or voiceless bilabial plosive followed by $[\mathrm{a}],[\mathrm{I}],[\varepsilon]$ or $[\mathrm{u}]$, then a plosive or fricative consonant followed by [I], [p] or [u] and closing with a consonant (for example: 'pidur'). Some class $\mathrm{C}$ words had a homorganic nasal or lateral consonant before the onset of the second syllable (for example: 'belsop'). There were two conditions: Prosody and No prosody. The two conditions are described further below.

This is a deviation from the standard AGL protocol which would typically present a continuous string of sounds only auditorily, with no prosody and without a narrative. This was done so that the cognitive demands of the task were minimized and the task could be understood by and administered to young typically developing children and children with learning difficulties. Children tend to be more attentive if characters appear and move on a screen than if they are only presented auditorily (Abrams \& Christ, 2003). A screenshot of the experiment is presented in Figure 1.

\section{INSERT FIGURE 1 ABOUT HERE}

Using these word classes, grammatical phrases could consist of two (AC) or three (ABC) words. Both $\mathrm{A}$ and $\mathrm{C}$ words must appear in a phrase for it to be grammatical. $C$ words must always follow $A$ words and $B$ words (if present) must follow $A$ words, precede $C$ words and could only be used if an $A$ word is present. Violations were generated by changing 
the order of word classes (for example: 'budoc subi lanel'), by repeating the same word class (for example: 'pafil budoc pidur') or by having both a word order change and a repetition (for example: 'pafil rana rana'). The task had two phases: a familiarisation phase and a judgment phase.

Familiarisation: Ten sentences were generated based on the artificial grammar using Cepstral's (Cepstral LLC, 2011) British English synthesised voice (Lawrence) configured to speak at a rate of 136 words per minute. This represents a slow typical speech rate (Tauroza \& Allison, 1990) in order to aid comprehension. All phrases were sampled at a rate of $44100 \mathrm{~Hz}, 16 \mathrm{bit}$ in stereo with intensity scaled to $70 \mathrm{~dB}$. In the No Prosody condition the fundamental frequency (F0) of the phrases was kept constant at $100 \mathrm{~Hz}$ using Praat (Boersma \& Weenink, 2005). In the Prosody condition, F0 fell across the phrase: the F0 of A words was $125 \mathrm{~Hz}, \mathrm{~B}$ words were at an $\mathrm{F} 0$ of $100 \mathrm{~Hz}$ and $\mathrm{C}$ words were $75 \mathrm{~Hz}$. There was a falling tone on the last word, and the first syllable was higher in pitch than the second syllable of the last word. Familiarisation trials were created and presented using Microsoft PowerPoint using adapted clipart images of a Magician and the animals from the artificial grammar scheme. Images were adapted using GNU Image Manipulation Program (GIMP 2.6).

Experimental Trials: Experimental trials were presented on a laptop computer using Eprime 2.0 Professional (Psychology Software Tools, Inc). At test, there were 10 ungrammatical and 10 grammatical phrases (see Appendix). The grammatical phrases consisted of six phrases from the familiarisation trials, and four new, unfamiliar phrases that followed the grammar scheme but were novel to that participant. The ungrammatical phrases consisted of repetitions of word classes (either the same word repeated or repetitions of the same word class) or violations of dependency rules (such as a B word followed by a B word). As in the familiarisation trials, in the Prosody condition the F0 of A words was $125 \mathrm{~Hz}, \mathrm{~B}$ words were at an $\mathrm{F} 0$ of $100 \mathrm{~Hz}$ and $\mathrm{C}$ words were $75 \mathrm{~Hz}$. This meant that the ungrammatical 
phrases were distinct from the grammatical phrases due to an unfamiliar F0 in addition to the violation at the syntactic level. In the No Prosody condition all phrases were presented at a F0 of $100 \mathrm{~Hz}$.

\subsection{Procedure}

Each participant was tested individually in a quiet room at the University of Reading or at the participant's school. Before the familiarisation phase, children were told that they were about to see a magician who would be practising his spells and all they had to do was to watch and listen to the spells. They were also told that the spells would sound funny because the magician comes from another planet. Participants were randomly assigned to the 'Prosody' or 'No prosody' condition. There were no significant differences between the WS participants in the prosody and in the no prosody conditions on their scores on the RCPM (Mann-Whitney U=.805), CELF-word structures (Mann-Whitney U =.536) or CA (MannWhitney $U=.442$ ). The non-verbal ability matched TD group in the prosody condition was not significantly different from the non-verbal ability matched TD group in the no-prosody condition on the RCPM (Mann-Whitney U=.863), CELF-word structures (Mann-Whitney $\mathrm{U}=.077$ ) or CA (Mann-Whitney $\mathrm{U}=.605$ ) and the age-matched TD group in the prosody condition did not significantly differ from the age-matched older TD group in the no-prosody condition on the RCPM (Mann-Whitney U=.078), CELF-word structures (Mann-Whitney $\mathrm{U}=.596$ ) nor on CA (Mann-Whitney $\mathrm{U}=.243$ ).

Previous studies using the AGL paradigm with child participants do not always report total familiarisation time; they report the number of times the training stimuli were presented (e.g. Gebauer \& Mackintosh, 2007). Of the studies which explicitly report the familiarisation time, there is some variation. Infants were familiarised for 2 minutes in Marcus et al., (1999) and in Saffran et al., (1996); children with and without developmental dyslexia (mean age 10 years 7 months) were familiarised in approximately 6 mins (Pavlidou, Williams, \& Kelly, 
2009). Based on previous research, and the fact that some of the participants in our study had learning difficulties, we decided on a familiarization phase of 7 minutes, after which the experimental trials were presented. The familiarisation phase was divided into 8 blocks, each lasting approximately 1 minute. The phrases were repeated on average 10 times (range 9-11) within the 8 minutes familiarisation. The phrases were presented along with corresponding animations in the PowerPoint presentation. Instructions were given throughout the familiarisation trials using synthesised speech with prosody, regardless of prosody condition. A game was used between each block to maintain participants' attention. These were simple games that involved the child clicking on animals, or finding objects, and also at the end of every two blocks the child got an award of "magic balls" to maintain motivation. These "magic balls" appeared on the screen and were all of a different colour.

In the test trials participants were told that the magician was teaching another magician some spells, and that sometimes these spells would be right and sometimes wrong. The child had to judge whether spells obeyed or violated the rules based on the resemblance to the familiarisation spells. If the participant judged the spell to be correct, they pressed a green smiling face on the keyboard; if they judged a spell to be incorrect, they pressed a red sad face on the keyboard. Subsequent to the judgement of grammaticality, participants saw an animation of the spell if it was grammatical; if it was ungrammatical, they saw an animated, amorphous, pink blob. These animations were independent of participants' responses in order to introduce no feedback to guide later judgements (there was no pattern with regard to specific animations indicating a correct or incorrect response).

At the end of each AGL session, the participant was asked to tell us how they knew which spells would work. None of them were able to report that they had spotted the pattern of how the spells worked. Children commonly responded with: "I was guessing" or "I don't know". 


\subsection{Data Analysis and Results}

\subsection{Data analysis}

We were interested in the effect of grammaticality of the test sequence, as defined by the target grammar, as well as in the effect of familiarity on acceptance/rejection behaviour of each group. Grammaticality is a binary variable: sequences were either grammatical or ungrammatical. In this experimental design, familiarity was also treated as a binary variable, as some grammatical test sequences appeared during familiarisation (hence they were familiar) and others did not (they were unfamiliar).

The first stage of data analysis was based on these binary distinctions and looked at responses to the sequence categories Grammatical/Familiar (GrF), Grammatical/Unfamiliar (GrU) and Ungrammatical (Ungr). Response data were converted to "D Scores" (Perruchet \& Pacteau, 1990; Zimmerer, et al., 2011). To calculate a measure of sensitivity to grammaticality, we used the following formula:

$$
\begin{aligned}
& D(\text { Grammaticality })=(\text { percentage of Ungr sequences rejected })-(\text { percentage of GrF } \\
& \text { and GrU sequences rejected })
\end{aligned}
$$

Given our interest in acceptance/rejection patterns based on familiarity, we calculated a second variable using the following formula:

$$
\begin{aligned}
& D(\text { Familiarity })=(\text { percentage of } G r U \text { sequences rejected })-(\text { percentage of } G r F \\
& \text { sequences rejected })
\end{aligned}
$$

For the familiarity D Score, and in order to avoid the confounding effect of ungrammatical sequences, we only considered grammatical sequences. D scores lie on a scale between -100 and 100, with 100 representing a perfect discrimination between grammatical and ungrammatical sequences, and zero representing chance. D scores allow easier 
comparison between grammaticality and familiarity scores. It should be noted that all twenty test sequences were included for grammaticality D Scores, while only ten (only the grammatical ones) were included for familiarity D scores. Both scores were calculated for each individual participant.

Over decades of AGL research, the use of interval familiarity variables has emerged as the "gold standard" (Brooks \& Vokey, 1991; Knowlton \& Squire, 1994; Pothos \& Bailey, 2000; Redington \& Chater, 1996). Instead of relying on a simple familiar/unfamiliar dichotomy, these variables allow to study the effects of degrees of familiarity. Our second stage of data analysis, which was carried out post-hoc, therefore included the effects of three types of interval familiarity variables. Associative Chunk Strength (ACS) describes the average frequency in which parts of a test sequence appear during familiarisation. It is common to average frequencies of bigrams and trigrams to calculate ACS (e.g., Christiansen, Kelly, Shillock, \& Greenfield, 2010). However, due to our stimulus sequences being only two or three words long, we averaged occurrences of single words and bigrams. We calculated Anchor Strength for the initial (AFI) and the final (ASF) word, which determines how often a familiarisation stimulus started or ended with the respective word. We also computed Edit Distance (ED), which is the minimum number of word insertions and deletions that have to occur to change a test sequence into one of the familiarisation sequences. For instance, the familiarisation sequence most similar to the test sequence "Ranos Surug Budoc" is "Ranos Seto Budoc". It requires one word deletion ("Surug") and one addition ("Seto") to transform the test sequence into the familiarization sequence. The ED for "Ranos Surug Budoc" is therefore 2.

This step of the analysis was item-based. Our independent variable was the proportion of participants from a particular group who accepted a stimulus string. As predictors, we selected each string's ACS, AFI, ASF, ED and Grammaticality (as a binary variable). We 
used forward stepwise regressions to investigate which variables determined participant behaviour. Forward stepwise regressions start building a model by including solely the best predictor, and add further predictors only if they significantly improve the model. We chose this stricter model because the novelty of this research meant that we had no basis to exclude variables before running the analysis and we did not want to obscure the potential impact of strong predictors.

\subsection{Results}

\subsubsection{Grammaticality and Familiarity D Scores}

Table 3 below shows the number of rejections (in percentage) of the grammatical and ungrammatical sequences, and within the grammatical ones, the number of rejections (in percentage) of familiar and unfamiliar sequences and the grammaticality and familiarity Dscores by the TD and WS groups. One-sample t-tests were run to investigate whether the grammaticality and familiarity D-scores differed significantly from zero.

\section{INSERT TABLE 3 ABOUT HERE}

As Table 3 shows, in the Prosody condition, the TD group when pooled together had a mean grammaticality D Score which was significantly higher than zero, $\mathrm{t}(32)=5.906, \mathrm{p}<.001$. Their mean familiarity D Score was also significantly higher than zero, $\mathrm{t}(32)=2.930, \mathrm{p}=.006$. With the groups split into NVMA and CA matched groups, it was only the CA matched TDP group which had a grammaticality D Score significantly higher than zero, $t(20)=7.129$, $\mathrm{p}<.001$ and a familiarity D Score was also significantly higher than zero, $\mathrm{t}(20)=2.715$, $\mathrm{p}=.013$. In the No-prosody condition, when the TD group was pooled together, their mean grammaticality D Score was significantly higher than zero, $\mathrm{t}(26)=7.638, \mathrm{p}<.001$ and their familiarity D Score was also significantly higher than zero, $t(26)=4.030, p<.001$. When the 
groups were split into NVMA and CA matched, the NVMA group's mean grammaticality D Score differed significantly from zero, $\mathrm{t}(9)=3.104, \mathrm{p}=.013$ and so did the mean familiarity $\mathrm{D}$ Score, $\mathrm{t}(9)=2.824, \mathrm{p}=.020$. The CA matched group's grammaticality D score was significantly higher than zero, $\mathrm{t}(16)=7.941, \mathrm{p}<.001$ and their familiarity mean D score was also significantly higher than zero, $\mathrm{t}(16)=2.855, \mathrm{p}=.011$. With the regard to the WS group, the mean grammaticality D Score was differed significantly from zero only in the prosody condition, $\mathrm{t}(7)=2.818, \mathrm{p}=.026$. The familiarity $\mathrm{D}$ score did not significantly differ from zero in neither condition.

\subsubsection{Between-group comparisons}

We compared the grammaticality and familiarity D scores of the TD group, both the prosody and no prosody subgroups (not split by RCPM scores), with the WS group (both prosody and no prosody subgroups) using a Kruskal-Wallis H. There were no statistically significant differences between the groups on familiarity D scores, $H(3)=4.397, p=.222$, but there was a significant difference between the groups on grammaticality D scores, H (3)= $10.839, \mathrm{p}=.013$. A series of two Mann--Whitney tests were conducted to investigate which groups significantly differ. The significance level was set at .025 , corrected to control for Type I error. There was a statistically significant difference with a large effect size between the TD and WS groups in the No-prosody condition, $\mathrm{U}=27.000, \mathrm{Z}=-3.198, \mathrm{p}=.001, \mathrm{r}=-$ .54. There was no difference between the grammaticality D-scores of the TD and WS groups in the prosody condition, $\mathrm{U}=113.500, \mathrm{Z}=-.613, \mathrm{p}=.550$.

The analysis was then run including the two TD subgroups (NVMA and CA). There was no statistically significant difference between the groups on familiarity D scores, $\mathrm{H}(5)=$ $4.791, p=.442$, but there was a statistically significant difference between the groups on grammaticality D scores, $\mathrm{H}(5)=20.652, \mathrm{p}=.001$. A series of three Mann-Whitney tests was 
conducted to investigate which groups differ. The significance level was set at .012, corrected to control for Type I error. In the Prosody condition, the WS group did not differ on grammaticality D scores from the NVMA TD group, $U=34.500, Z=-1.067, p=.286$ neither did it differ from the CA matched TD group, $\mathrm{U}=52.000, \mathrm{Z}=-1.572, \mathrm{p}=.116$. In the Noprosody condition, there was no statistically significant difference between the WS group and the NVMA TD group, $\mathrm{U}=15.500, \mathrm{Z}=-2.189, \mathrm{p}=.029$, however there was a statistically significant difference with a large effect size between the WS group and the CA matched TD group, $\mathrm{U}=11.500, \mathrm{Z}=-3.314, \mathrm{p}=.001, \mathrm{r}=-.66$.

Tables 4 and 5 present one-tailed Spearman's correlations between D Scores and chronological age, RCPM scores and scores from the CELF word structure subtest (prosody and no-prosody conditions were pooled, both TD subgroups were pooled together). In the TD group, Grammaticality D Scores were significantly and positively correlated with age, RCPM and language ability as measured by the Word Structure/Formulated sentences subtest of the CELF. Chronological age, RCPM and Word Structure scores significantly correlated with each other. In the WS group, Grammaticality D scores were only correlated positively with percentage correct CELF scores.

\section{INSERT TABLE 4 AROUND HERE}

\section{INSERT TABLE 5 AROUND HERE}

Post-hoc stepwise linear regressions were calculated to determine predictors for D Scores in each group (TD and WS). The independent variables were the children's chronological age in months, RCPM and their percentage correct scores on the CELF Word Structures/Formulated sentences subtest. In the TD group, one variable significantly predicted $34 \%$ of the variance in grammaticality $D$ Scores, $\left[R^{2}=.341, F(1,54)=27.225\right.$, $\mathrm{p}<.001]$. This was CA, which significantly predicted grammaticality D Scores, $\beta=.583$, 
$\mathrm{p}<.001$, as children who were older were better at distinguishing grammatical from ungrammatical sequences. The regression model did not significantly improve when adding further predictors. In the WS group, a different variable significantly predicted $30 \%$ of the variance in grammaticality $\mathrm{D}$ scores, $\left[\mathrm{R}^{2}=.301, \mathrm{~F}(1,13)=5.033, \mathrm{p}=.045\right]$, i.e. CELF $(\%$ correct) significantly predicted grammaticality $D$ scores, $\beta=.544, p=.045$. There were no significant predictors of familiarity D Scores in either group.

\subsection{Analysis using continuous familiarity variables}

Using the continuous measures of familiarity, i.e., Associative Chunk Strength (ASC), Anchor Strength for the Initial (ASI), Anchor Strength for the Final (ASF) word and Edit Distance (ED), separate stepwise multiple regressions were carried for each of the groups: TDP (entire group and subgroups), TDNP (entire group and subgroups), WSP and WSNP. Regressions were item based: for each test sequence, we entered its Grammaticality, ACS, ASI, ASF and ED as predictor variables (see table 6). The dependent variable was the percentage of children that accepted the sequence in a given participant group.

For the TDP group, one predictor explained $86 \%$ of the variance, $\mathrm{R}^{2}=.858$, $\mathrm{F}(1,19)=108.709, \mathrm{p}<.001$. Grammaticality significantly predicted whether sequences were accepted or rejected, $\beta=.93, p<.001$. For the NVMA matched TDP participants, none of the variables predicted whether sequences were accepted or rejected. In the CA matched TDP group, two variables explained $92 \%$ of the variance, $\mathrm{R}^{2}=.921, \mathrm{~F}(1,17)=99.214, \mathrm{p}<.001$. The strongest predictor was Grammaticality, $\beta=.77, p<.001$. The other predictor was ED, $\beta=.24$, $\mathrm{p}=.038$.

For the TDNP group, two predictors explained $83 \%$ of the variance, $\mathrm{R}^{2}=.828$, $\mathrm{F}(2,17)=46.811, \mathrm{p}<.001$. Grammaticality of sequences significantly predicted whether they were accepted, $\beta=.54, p=.002$. The second predictor was $E D, \beta=.44, p=.008$. In the NVMA 
matched TDNP group, one predictor explained $64 \%$ of the variance in whether test sequences were accepted or rejected: $R^{2}=.636, F(1,18)=31.401, p<.001$. The predictor was $E D, \beta=.80$, $\mathrm{p}<.001$. In the CA matched TDNP group, two predictors explained $87 \%$ of the variance, $\mathrm{R}^{2}=.869$. The strongest predictor was Grammaticality, $\beta=.66, \mathrm{p}<.001$. The second predictor was $\mathrm{ED}, \beta=.32, \mathrm{p}=.03$.

For the WSP group, analysis revealed that one predictor explained $53 \%$ of the variance, $\mathrm{R}^{2}=.529, \mathrm{~F}(1,18)=20.216, \mathrm{p}<.001$. ED significantly predicted whether sequences were accepted or rejected, $\beta=.73, p<.001$. For the WSNP group, analysis revealed no predictors at significant levels.

\section{INSERT TABLE 6 AROUND HERE}

\subsection{Discussion}

This study used a child-friendly AGL paradigm to investigate whether individuals with WS were able to extract patterns in structured sequences of synthetic speech, how they compared to TD children, and whether prosodic cues affected learning. Importantly, the study aimed to establish whether children with WS focussed on different aspects of structure (grammaticality vs familiarity) compared to TD children. The main findings are: 1) the TD group (taken as a whole) outperformed the WS group with regard to grammaticality based judgements. However, once the WS group was matched on non-verbal ability to a subset of the TD group, there was no difference between the TD and WS groups; 2) the behaviour of the participants with WS seems to be driven by familiarity (item-based generalisation), while the behaviour of the TD children seems to be predominantly driven by grammaticality, i.e. rule-based generalisations; 3) in the absence of prosodic cues, children with WS did not demonstrate evidence of learning. The non-verbal ability matched TD children, however, showed the opposite pattern, whereby they showed evidence of learning when no prosody 
was present and no evidence of learning when prosodic cues were present; 4) within the TD group, evidence for rule-based generalisations was stronger in the age-matched subgroup (mean age 8 years 7 months), which had higher non-verbal ability. The evidence for rulebased generalisations for the non-verbal ability matched subgroup (mean age 5 years 1 month) was weaker. We elaborate on each of these main findings below.

When considered as a whole, the TD group outperformed the WS group with regard to their use of grammaticality when making judgments about the acceptability of sequences. This is not surprising, given that the TD group had significantly higher verbal and non-verbal abilities. When some of the differences between the groups were eliminated, and the WS group was compared only to those TD individuals who were matched on non-verbal abilities, the WS did not differ from the TD group with regard to their reliance on grammaticality when making judgements about the acceptability of sequences. These findings are in line with those of Don et al. (2003), who also reported that TD individuals outperformed individuals with WS on two implicit learning tasks, one of which was an AGL task.

Of the familiarity variables tested, Edit Distance (ED) explained much of the behaviour in the WS group, and in the non-verbal ability matched TD groups, but only in the no-prosody condition (the issue of the possible role of prosody will be discussed separately). AGL behaviour driven by ED is regarded as evidence for exemplar-based processing, in which sequences are not segmented but stored as a single unit (Perruchet, 1994; Pothos, 2007). This means that acceptability of test stimuli is dependent on how similar the form is to the one of the learned exemplars. It seems that, unlike TD children, who appear to change processing biases from familiarity to grammaticality based between the ages of 5 and 7 , children and adolescents with WS, who in this study were aged between 6 and 18, retain a bias towards familiarity until they are much older. Whether the processing bias changes later 
into adolescence or early adulthood in WS would need to be investigated in adolescents and adults with WS.

Our findings are in line with those reported by Thomas, et al., (2001) who investigated past-tense formation in individuals with WS, the English past tense being a paradigm which contrasts rule-based (regular forms) and exemplar-based processing (irregular forms). They reported that individuals with WS performed equally on both regular and irregular forms, and importantly, when controlled for verbal mental ager, the WS group were weaker at generalising the "add-ed" rule to novel forms, suggesting exemplar-based instead of rule-based processing.

There is evidence from domains other than language that individuals with WS have difficulties processing complex arrangements at a 'global' level, i.e., as the sum of their parts. For example, when given a task in which they are required to draw a picture, individuals with WS tend to produce different elements without connecting these to make a whole (Wang, Doherty, Rourke \& Bellugi, 1995). A number of studies have argued that individuals with WS focus on local rather than the global characteristics of visual stimuli (Bihrle, Bellugi, Delis, \& Marks, 1989; Bellugi et al., 1994, 1999; Deruelle, Mancini, Livet, Cassé Perrot, \& de Schonen, 1999). Furthermore, a recent ERP study by Key and Dykens (2011) provides evidence that the brain mechanisms underlying attention to local information during the early stages of perceptual analysis, and at the more advanced stages of cognitive processing, are atypical in WS. With regard to auditory processing, Deruelle, Schön, Rondan, and Mancini (2005) reported that children with WS did not show the typical global precedence in music processing observed in TD children. While TD children were better at detecting the difference between two melodies in a contour-violated than in an interval-violated condition, the individuals with WS performed equally in both conditions. A recent study by Elsabbagh et al. (2010) also showed that adolescents and adults with WS, unlike TD individuals, did not 
rely on contour cues in unfamiliar melody perception suggesting absence of use of global processing in music.

Although the above studies focus on visual and music processing, we could hypothesise that similar processing biases might apply in the processing of language-like auditory stimuli. Certain commonalities between language and music have been suggested in that they may share similar developmental mechanisms (McMullen \& Saffran, 2004; Trehub, 2003). Given that evidence suggests that individuals with WS tend to have a local processing bias with music, it is not surprising to find a similar bias with language-like stimuli. Furthermore, the WS brain develops atypically at different levels, including anatomy, biochemistry and functional connectivity, and it is characterised with different spatial and temporal patterns compared with neuro-typical brains (Karmiloff-Smith, 2012). It is, therefore, plausible that individuals with WS may be processing auditory stimuli differently from TD children. This does not automatically imply that individuals with WS are 'local' processors in general, as some earlier studies would have suggested (e.g. Bellugi, et al.,2000; Farran, et al., 2003; Wang, Mottron, Peng, Berthiaume \& Dawson, 2007). A recent study by D’Souza, et al. (2015) shows, in a series of tasks, that individuals with neurodevelopmental disorders, including WS, have both global and local processing biases, depending on the task and stimuli. Also, an earlier study by Pani, Mervis and Robinson (1999) observed that adults with WS organised spatial displays at a global level and found it more difficult than typical controls to change from global to local processing. Hence, the preference for exemplar-based processing applies as far as the AGL task in our study is concerned and the specific languagelike stimuli employed.

Another novel finding from the study was related to the differences between the WS and TD groups with regard to the effect of prosody in learning an artificial grammar. Unlike traditional AGL tasks, we included a prosody manipulation element to find out whether 
prosody would facilitate the learning of an artificial grammar. We found that, indeed, for the children with WS, prosody may have a significant facilitating effect compared to TD controls, and especially when compared to the non-verbal ability matched TD controls.

Such a finding fits well within the hierarchical framework of speech segmentation cues proposed by Mattys, et al., (2005), in which it is suggested that segmentation cues are hierarchically integrated so that lexical cues are preferred over segmental, and these are preferred over prosodic cues (the prosodic cues being the lowest in the hierarchy). They further suggest that "the lower weighted cues in adult speech segmentation seem to be the earliest and hence the most critical ones at the onset of language development" (p.493). A rich body of literature supports this view showing that young learners use prosody to cue the locations of syntactically relevant units, such as phrases and clauses, and to identify the structural relations among these units (e.g., Brown, 1973; Fisher, 1991; Gleitman, Gleitman, Landau \& Wanner, 1988; Hirsh-Pasek et al., 1987; Jusczyk et al., 1992; Morgan, et al., 1987). It appears that individuals with WS seem to be 'stuck' in the lowest part of the hierarchy (prosodic cues) where they need prosodic cues in order to be able to make reliable acceptability judgments. And because of their strong preference for local processing, they need the prosodic cues to help them decide which sequences are acceptable. We suspect that the emergence of the grammaticality bias in language processing, which seems to start around age 5, reduces the need for prosodic cues in TD children, hence they do not benefit from prosodic cues in the same way as children with WS.

The last finding relates to differences between non-verbal ability matched and agematched TD children with regard to AGL. One of the assumptions in the past has been that older children and adults use the same mechanisms when acquiring artificial grammar as nonverbal ability matched children (Ingram \& Pye, 1993). However, to our knowledge, studies so far have not compared younger and older TD children. Our study filled this gap and found 
that non-verbal ability matched (and subsequently younger TD children) and age -matched (and subsequently older TD children) have different processing preferences when making their judgments, in that children (with a similar NVMA to the children with WS (and subsequently younger) tend to rely on familiarity, and older children (similar to the WS on CA) tend to rely on grammaticality when judging the acceptability of test stimuli. None of the children tested in our experiment reported knowledge of any structure, which suggests that learning was implicit. It is already known that processing biases change from local to global sometime between the ages of 6 and 10 (Mondloch, et al., 2002; Poirel, et al., 2008). If this is the case, our results imply that implicit learning as measured by an AGL task changes at a qualitative level during maturation. The literature is inconclusive as to how age and IQ may influence implicit learning, with some studies showing that age does not affect implicit learning (Thomas \& Nelson, 2001; Vinter \& Perruchet, 2000); however, others have reported that chronological age is related to implicit learning (Maybery, Taylor \& O’Brien-Malone, 2005). A large-scale study employing the AGL paradigm to a group of 605 TD children reported that performance in an AGL task did not correlate with various measures of intelligence (Gebauer \& Mackintosh, 2007). However, studies which have included children with intellectual disabilities show that implicit learning is related to mental age (MA) (Fletcher, Maybery \& Bennett, 2000), as well as non-verbal intelligence and working memory (Don et al., 2003). Our current study is not in a position to investigate the effects of age and non-verbal abilities in isolation; however, the data suggest a relationship between chronological age and implicit learning as measured by an AGL task for the TD group, in that $34 \%$ of the variance in acceptance of grammatical sequences was explained by chronological age. In the WS group, language ability as measured by a subtest of the CELF was the only variable which positively correlated with grammaticality D scores and explained $30 \%$ of the 
variance in grammaticality D scores, suggesting a possible relationship between implicit learning as measured by our AGL task and language ability.

The findings from the study provide evidence that language learning in children with WS may be qualitatively different from that of TD, and that these differences may be related to their general cognitive profiles. In particular, AGL behaviour in WS appears different both with regard to the type of sequence information processed and with regard to their reliance on prosody. It is impossible to know from the current study exactly how the familiarity (exemplar-based) processing bias found in the AGL task may be related to other nonlanguage aspects of cognition, but it may possibly explain why the general language skills (except for receptive vocabulary) in individuals with WS rarely exceed those of typical 5-7 year olds (Grant, Valian \& Karmiloff-Smith., 2002). It is also possible that the fact that general cognitive abilities in WS rarely develop higher than what would be expected of a typical 5-7 year old child means that the most readily available route to language learning is the one that is typical of this level of general cognitive ability.

A non-trivial limitation of the current study is the relatively small number of individuals with WS which arose from the limitation of participant availability within a relatively limited age range and in a relatively small geographical area (due to the fact that we used Southern British English intonation in the prosody condition), as well as the rarity of the condition. A larger study including slightly older individuals with WS to cover adolescents and adults with WS is needed to complete the picture and address questions about the relationship between general cognitive factors and language acquisition in WS. Also we did not collect data on participants' engagement in musical activities and it is possible that engagement in music activities may have been related to children's sensitivity to prosodic cues, especially in the WS group. 


\section{Acknowledgments}

This project was funded by the British Academy (project number BR100076) and the University of Reading. We would also like to thank all the children who participated, and all their parents and teachers who helped support this research project. We are grateful to the Williams Syndrome Foundation in the UK for their continued support, Rachel Sparring, Fiona Hobler and Hannah Miles for help with the data collection, Isobel Baker for her contribution towards the data analysis and Joanne Cleland for her contribution to the design of the study.

\section{References}

Abrams, R. A., \& Christ, S. E. (2003). Motion onset captures attention. Psychological Science, 14(5), 427-432. doi: 10.1111/1467-9280.01458.

Beach, C. M., Katz, W. F., \& Skowronski, A. (1996). Children's processing of prosodic cues for phrasal interpretation. The Journal of the Acoustical Society of America, 99(2), $1148-1160$

Bellugi, U., Bihrle, A., Neville, H., Jernigan, T., \& Doherty, S. (1992). Language, cognition, and brain organization in a neurodevelopmental disorder. In Gunnar, M., \& Nelson, C. (Eds.), Developmental behavioural neuroscience, (pp.201-232). Hillside, NJ: Lawrence Erlbaum Associates, Inc.

Bellugi, U., Lichtenberger, L., Jones, W., Lai, Z., \& St George, M. (2000). I. The neurocognitive profile of Williams Syndrome: a complex pattern of strengths and weaknesses. Cognitive Neuroscience, Journal of, 12(Supplement 1), 7-29. doi: $10.1162 / 089892900561959$ 
Bellugi, U., Lichtenberger, L., Mills, D., Galaburda, A., \& Korenberg, J.R. (1999). Bridging cognition, the brain and molecular genetics: evidence from Williams syndrome. Trends in Neurosciences, 22(5), 197-207. doi: 10.1016/S0166-2236(99)01397-1.

Bellugi, U., Sabo, H., \& Vaid, J. (1988). Spatial deficits in children with Williams syndrome. In J. Stiles-Davis, U. Kritchevshy, \& U. Bellugi (Eds.), Spatial cognition: Brain bases and development (pp. 273-297). Hillsdale, New Jersey: Lawrence Erlbaum.

Bellugi, U., Wang, P.P., \& Jernigan, T.L. (1994). Williams syndrome: An unusual neuropsychological profile. In Broman, S. \& Grafman, J. (Eds.) Atypical cognitive deficits in developmental disorders: Implications for brain function. (pp.23-56). Hillsdale, New Jersey: Lawrence Erlbaum Associates.

Bihrle, A. M., Bellugi, U., Delis, D., \& Marks, S. (1989). Seeing either the forest or the trees: Dissociation in visuospatial processing. Brain and Cognition, 11(1), 37-49. doi: $10.1016 / 0278-2626(89) 90003-1$.

Boersma, P., \& Weenink, D. (2005). Praat: doing phonetics by computer (Version 4.3.01) [Computer program]. Retrieved from http://www.praat.org/.

Brock, J. (2007). Language abilities in Williams syndrome: A critical review. Development and Psychopathology, 19(1), 97-127. doi: 10.1017/S095457940707006X.

Brooks, L. R., \& Vokey, J. R. (1991). Abstract analogies and abstracted grammars: Comments on Reber (1989) and Mathews et al. (1989). Journal of Experimental Psychology: Learning, Memory, and Cognition, 17, 316-323. doi: 10.1037/00963445.120.3.316.

Brown, R. (1973). A first language: The early stages. London: George Allen \& Unwin. Capirci, O., Sabbadini, L., \& Volterra, V. (1996). Language development in Williams syndrome: A case study. Cognitive Neuropsychology, 13, 1017-1039. doi: $10.1080 / 026432996381764$ 
Catterall, C., Howard, S., Stojanovik, V., Szczerbinski, M., \& Wells, B. (2006). Investigating prosodic ability in Williams Syndrome. Clinical Linguistics and Phonetics. 20, 7-8, $531-538$.

Christiansen, M. H., Kelly, L. M., Shillock, R., \& Greenfield, K. (2010). Impaired artificial grammar learning in agrammatism. Cognition, 116(3), 382-393. doi: 10.1016/j.cognition.2010.05.015.

Conway, C. M., Bauernschmidt, A., Huang, S. S., \& Pisoni, D. B. (2010). Implicit statistical learning in language processing: Word predictability is the key. Cognition, 114, 356371. doi: :10.1016/j.cognition.2009.10.009.

Deruelle, C., Mancini, J., Livet, M. O., Cassé Perrot, C., \& de Schonen, S. (1999). Configural and local processing of faces in children with Williams syndrome. Brain and Cognition, 41, 276-298. doi:10.1006/brcg.1999.1127.

Deruelle, C., Schon, D., Rondan, C., \& Mancini, J. (2005). Global and local music perception in children with Williams syndrome. Neuroreport, 16, 631-634.

Dominey, P. F., Hoen, M., Blanc, J-M., \& Lelekov-Boissard, T. (2003). Neurological basis of language and sequential cognition: evidence from simulation, aphasia, and ERP studies. Brain and Language, 86(2), 207-225. doi: 10.1016/S0093-934X(02)00529-1.

Don, A. J., Schellenberg, E. G., Reber, A. S., Di Girolamo, K. M., \& Wang, P. P. (2003). Implicit learning in children and adults with Williams syndrome. Developmental Neuropsychology, 23(1\&2), 201-225. doi: 10.1207/S15326942DN231\&2_9.

D’Souza, D., Booth, R., Connolly, M., Happé, F., \& Karmiloff-Smith, A. (2015). Rethinking the concepts of "local or global processors": Evidence from Williams syndrome, Down syndrome, and Autism Spectrum Disorders. Developmental Science. doi: $10.1111 /$ desc. 12312 
D’Souza, D. H., Moretti-Ferreira, D., \& Rugolo, L. M. S. S. (2007). Fluorescent in situ hybridization (FISH) as a diagnostic tool for Williams-Beuren syndrome. Genetics and Molecular Biology, 30(1), 17-20. doi: 10.1590/S1415-47572007000100005.

Elsabbagh, M., Cohen, H., \& Karmiloff-Smith, A. (2010). Discovering structure in auditory input: Evidence from Williams syndrome. American Journal on Intellectual and Developmental Disabilities, 115(2), 128-139. doi:10.1352/1944-7558-115.2.128

Farran, E. K., Jarrold, C., Gathercole, S. E. (2003). Divided attention, selective attention and drawing: processing preferences in Williams syndrome are dependent on the task administered. Neuropsychologia, 41(6), 676-687. doi: 10.1016/S00283932(02)00219-1.

Fletcher, J., Maybery, M.T., \& Bennett, S. (2000). Implicit learning differences: A question of developmental level? Journal of Experimental Psychology: Learning, Memory, \& Cognition, 26(1), 246-252. doi: 10.1037/0278-7393.26.1.246.

Gebauer, G. F., \& Mackintosh, N. J. (2007). Psychometric intelligence dissociates implicit and explicit learning. Journal of Experimental Psychology: Learning, Memory, and Cognition, 33(1), 34-54. doi: 10.1037/0278-7393.33.1.34.

Gleitman, L. R., Gleitman, H., Landau, B., \& Wanner, E. (1988). Where learning begins: Initial representations for language learning. In F. J. Newmeyer (Ed.), Linguistics: The Cambridge survey, Vol. 3. Language: Psychological and biological aspects (pp. 150-193). New York: Cambridge University Press.

Goharpey N, Tsoutsoulis K.,\& Crewther S.G. (2012). Raven’s Coloured Progressive Matrices performance as a valid predictor of cognitive and motor delay in Intellectual Disability regardless of etiology. Front. Hum. Neurosci. Conference Abstract: ACNS- 
2012 Australasian Cognitive Neuroscience Conference. doi:

10.3389/conf.fnhum.2012.208.00196

Grant, J., Valian, V., \& Karmiloff-Smith, A. (2002). A study of relative clauses in Williams syndrome. Journal of Child Language, 29, 403-416.doi: 10.1017/S030500090200510X.

Greenberg, E. (1990). Introduction to special issue on Williams syndrome. American Journal of Medical Genetics Supplement, 6, 85-88.

Grice, S. J., de Haan, M., Halit, H., Johnson, M., Csibra, G., Grant, J., \& Karmiloff-Smith, A. (2003). ERP abnormalities of illusory contour perception in Williams syndrome. NeuroReport, 14, 1773-1777. doi: 10.1097/01.wnr.0000094161.86963.c5.

Hirsh-Pasek, K., Kemler-Nelson, D. G., Jusczyk, P. W., Cassidy, K. W., Druss, B., \& Kennedy, L. (1987). Clauses are perceptual units for young infants. Cognition, 26, 269-286. doi: 10.1016/S0010-0277(87)80002-1.

Ingram, D., \& Pye, C. (1993). The acquisition of miniature languages: The search for a new paradigm. International Journal of Psycholinguistics, 9(2), 147-158.

Joffe, V., \& Varlokosta, S. (2007). Patterns of syntactic development in children with Williams syndrome and Down's syndrome: Evidence from passives and whquestions. Clinical Linguistics \& Phonetics, 21(9), 705-727.doi: 10.1080/02699200701541375.

Jusczyk, P. W., Friederici, A. D. Wessels, J., Svenkerud, V. Y., \& Jusczyk, A. M. (1993). Infants' sensitivity to the sound patterns of native language words. Journal of Memory and Language, 32, 402-420. doi: 10.1006/jmla.1993.1022.

Jusczyk, P. W., Hirsch-Pasek, K., Kemler Nelson, D. G., Kennedy, L. J., Woodward, A., \& Piwoz, J. (1992). Perception of acoustic correlates of major phrasal units by young infants. Cognitive Psychology, 24(2), 252-293.doi: 10.1016/0010-0285(92)90009-Q. 
Karmiloff-Smith, A. (2012). Perspectives on the dynamic development of cognitive capacities: insights from Williams syndrome. Current Opinion in Neurology, 25, 106-111. doi: 10.1097/WCO.0b013e3283518130.

Karmiloff-Smith, A., \& Farran, E. (2012). Williams syndrome: A model for the neuroconstructivist approach. In E. Farran \& A.Karmiloff-Smith (2012), (Eds.), Neurodevelopmental disorders across the lifespan: A neuroconstructivist approach. (pp. 1-10). Oxford: OUP.

Karmiloff-Smith, A., Thomas, M., Annaz, D., Humphreys, K., Ewing, S., Brace, N., van Duuren, M., Pike, G., Grice, S., \& Campbell, R. (2004). Exploring the Williams syndrome face-processing debate: The importance of building developmental trajectories. Journal of Child Psychology and Psychiatry, 45(7), 1258-1274. doi: 10.1111/j.1469-7610.2004.00322.x.

Key, A. P., \& Dykens, E. M. (2011). Electrophysiological study of local/global processing in Williams syndrome. Journal of Neurodevelopmental Disorders, 3(1), 28-38. doi: 10.1007/s11689-010-9064-1.

Knowlton, B. J., \& Squire, L. R. (1994). The information acquired during artificial grammar learning. Journal of Experimental Psychology. Learning, Memory, and Cognition, 20(1), 79-91. doi: 10.1037/0278-7393.20.1.79.

Lenhoff, H. (1998). Insights into the musical potential of cognitively impaired people diagnosed with Williams syndrome. Music Therapy, 16, 333-336.

Levitin, D. J., \& Bellugi, U. (1998). Musical abilities in people with Williams syndrome. Music Perception, 15, 357-389.

Levitin, D. J., Cole, K., Chiles, M., Lai, Z., Lincoln, A., \& Bellugi, U. (2004). Characterizing the musical phenotype in individuals with Williams syndrome. Child Neuropsychology, 10, 223-247. 
Maratsos, M. P., \& Chakley, M. (1980). The internal langauge of children's syntax: The ontogenesis and representtaion of syntactic categories. In K. Nelson (Ed.), Children's language (Vol. 2, pp. 127-214). New York: Gardner.

Marcus, G. F., Vijayan, S., Rao, S. B., \& Vishton, P. M. (1999). Rule learning by sevenmonth-old infants. Science, 283(5398), 77-80.

Martinez-Castilla., P., Stojanovik, V., Setter, J., \& Sotillo, M. (2012) Prosodic abilities in Spanish and English children with Williams syndrome: A Cross-linguistic study. Applied Psycholinguistics. 33, 1-12

Mattys, S. L., White, L., \& Melhorn, J. F. (2005). Integration of multiple speech segmentation cues: A hierarchical framework. Journal of Experimental Psychology: General, 134, 477-500. doi: 10.1037/0096-3445.134.4.477.

McMullen, E., \& Saffran, J. (2004). Music and language: A developmental comparison. Music Perception, 21, 289-311

Mervis, C. B., \& Becerra, A. M. (2007). Language and communicative development in Williams syndrome. Mental Retardation and Developmental Disabilities Research Reviews, 13, 3-15. doi: 10.1002/mrdd.20140.

Mervis, C.B., \& John, A.E. (2008). Vocabulary abilities of children with Williams syndrome: Strengths, weaknesses, and relation to visuospatial construction ability. Journal of Speech, Language, and Hearing Research, 51(4), 967-982. doi: 10.1044/10924388(2008/071).

Mervis, C. B. \& John, A. E. (2012). Precursors to language and early language. In E. Farran \& A. Karmiloff-Smith (2012), (Eds.), Neurodevelopmental disorders across the lifespan: A neuroconstructivist approach. (pp. 187-204). Oxford: OUP. 
Mervis, C.B., \& Klein-Tasman, B. P. (2000). Williams syndrome: cognition, personality, and adaptive behaviour. Mental Retardation and Developmental Disabilities Research Reviews, 6(2), 148-158.

Mervis, C. B., Robinson, B. F., Rowe, M. L., Becerra, A. M., \& Klein-Tasman, B. P. (2004). Relations between language and cognition in Williams syndrome. In Bartke S. \& Siegmüller J. (2004), (Eds.) Williams syndrome across languages. (pp 63-92.) Amsterdam: John Benjamins.

Maybery, M. T., Taylor, M. \& O'Brien-Malone, A. (1995) Implicit learning: Sensitive to age but not IQ. Australian Journal of Psychology, 47(1), 8-17. doi: $10.1080 / 00049539508258763$.

Mobbs, D., Eckert, M. A., Menon, V., Mills, D., Korenberg, J., Galaburda, A. M. \& Reiss, A. L. (2007). Reduced parietal and visual cortical activation during global processing in Williams syndrome. Developmental Medicine \& Child Neurology, 49(6), 433-438. doi: 10.1111/j.1469-8749.2007.00433.x

Mondloch, C.J., Le Grand, R., \& Maurer, D. (2002). Configural face-processing develops more slowly than featural face-processing. Perception, 31, 553-566.doi: 10.1068/p3339.

Morgan, J. L., Meier, R. P., \& Newport, E. L. (1987). Structural packaging in the input to language learning: Contributions of prosodic and morphological marking of phrases to the acquisition of language. Cognitive Psychology, 19, 498-550. doi: 10.1016/00100285(87)90017-X.

Nazzi, T., Paterson, S.J., \& Karmiloff-Smith, A. (2003). Word segmentation by infants with Williams syndrome. Infancy, 4, 251-271. doi: 10.1207/S15327078IN0402_06.

Pani, J.R., Mervis, C.B., \& Robinson, B.F. (1999). Global spatial organization by individuals with Williams syndrome. Psychological Science, 10, 453-458.

Patel, A. (2003). Language, music, and the brain. Nature Neuroscience, 6, 674-681. 
Pavlidou, E. V., Williams, J. M., \& Kelly, L. M. (2009). Artificial grammar learning in primary school children with and without developmental dyslexia. Annals of Dyslexia, 59(1), 55-77. doi:10.1007/s11881-009-0023-z

Perruchet, P. (1994). Defining the knowledge units of a synthetic language: comment on Vokey \& Brooks (1992). Journal of Experimental Psychology: Learning, Memory and Cognition, 20, 223-228.

Perruchet, P., \& Pacteau, C. (1990). Synthetic grammar learning: Implicit rule abstraction or explicit fragmentary knowledge? Journal of Experimental Psychology: General, 119, 264-275. doi: 10.1037/0096-3445.119.3.264.

Petersson, K. M., Folia, V., \& Hagoort, P. (2012). What artificial grammar learning reveals about the neurobiology of syntax. Brain and Language, 120, 83-95. doi:10.1016/j.bandl.2010.08.003.

Petersson, K. M., Forkstam, C., \& Ingvar, M. (2004). Artificial syntactic violations activate Broca's region. Cognitive Science, 28(3), 383-407. doi:10.1207/s15516709cog2803_4

Pinker, S. (1984). Language learnability and language development. Cambridge: Harvard University Press.

Poirel, N., Mellet, E., Houdé, O., \& Pineau, A. (2008). First came the trees, then the forest: developmental changes during childhood in the processing of visual local-global patterns according to the meaningfulness of the stimuli. Developmental Psychology, 44, 245-253. doi: 10.1037/0012-1649.44.1.245

Pothos, E. M. (2007). Theories of artificial grammar learning. Psychological Bulletin, 133, 227-244. doi: 10.1037/0033-2909.133.2.227. 
Pothos, E. M., \& Bailey, T. M. (2000). The importance of similarity in artificial grammar learning. Journal of Experimental Psychology: Learning, Memory, and Cognition, 26, 847-862. doi: 10.1037/0278-7393.26.4.847.

Raven, J. (2007). Coloured Progressive Matrices. London: Harcourt Publishers.

Reber, A. S. (1967). Implicit learning of artificial grammars. Verbal Learning and Verbal Behavior, 5(6), 855-863. doi: 10.1016/s0022-5371(67)80149-x.

Redington, M., \& Chater, N. (1996). Transfer in artificial grammar learning: A reevaluation. Journal of Experimental Psychology: General, 125(2), 123-138. doi: 10.1037/00963445.125.2.123.

Reilly, J., Klima, E. S., \& Bellugi, U. (1990). Once more with feeling: affect and language in atypical populations. Development and Psychopathology, 2, 367-391.

Saffran, J. R., Aslin, R. N., \& Newport, E. L. (1996). Statistical learning by 8-month-old infants. Science, 274(5294), 1926-1928.

Semel, E., Wiig, E. H., \& Secord, W. A. (2004). Clinical Evaluation of Language Fundamentals - 4 (CELF-4). Toronto, Canada: The Psychological Corporation/ A Harcourt Assessment Company.

Semel, E., Wiig, E. H., \& Secord, W. A. (2006). Pre-School Clinical Evaluation of Language Fundamentals - 2 (Pre-School CELF-2). Toronto, Canada: The Psychological Corporation/ A Harcourt Assessment Company.

Setter, J., Stojanovik, V.,van Ewijk, L., \& Moreland, M. (2007). Affective prosody in children with Williams syndrome. Clinical Linguistics and Phonetics. 9, 659-672.

Snedeker, J. \& Trueswell, J. C. (2001). Unheeded cues: Prosody and syntactic ambiguity in mother-child communication. Paper presented at the 26th Boston University Conference on Language Development, Boston, MA 
Stevens, T., \& Karmiloff-Smith, A. (1997). Word learning in a special population: Do individuals with Williams syndrome obey lexical constraints? Journal of Child Language, 24(3), 737-765.

Stojanovik, V. (2010). Understanding and production of prosody in children with Williams syndrome: A developmental trajectory approach. Journal of Neurolinguistics, 23(2), 112-126. Doi: 10.1016/j.jneuroling.2009.11.001

Stojanovik, V. (2012). Later language. In E. Farran \& A.Karmiloff-Smith (2012), (Eds.), Neurodevelopmental disorders across the lifespan: A neuroconstructivist approach. (pp. 205-223). Oxford: OUP.

Stojanovik, V., Setter, J., \& van Ewijk, L. (2007). Intonation abilities in children with Williams syndrome A preliminary investigation. Journal of Speech, Language and Hearing Research. 50, (6), 1610-1617.

Stojanovik, V., Perkins, M., \& Howard, S. (2004). Williams syndrome and specific language impairment do not support claims for developmental double dissociations and innate modularity. Journal of Neurolinguistics, 17(6), 403-424. doi:

10.1016/j.jneuroling.2004.01.002

Stojanovik, V., Setter, J., \& van Ewijk, L. (2007). Intonation abilities in children with Williams syndrome : A preliminary investigation. Journal of Speech, Language and Hearing Research. 50, (6), 1610-1617.

Strømme, P., Bjømstad, P.G., \& Ramstad, K. (2002). Prevalence estimation of Williams syndrome. Journal of Child Neurology, 17(4), 269-271. doi: 10.1177/088307380201700406.

Tassabehji, M., Metcalfe, K., Karmiloff-Smith, A., Carette , M. J., Grant , J., Dennis, N., et al., (1999). Williams syndrome: Use of chromosomal micro-deletions as a tool to 
dissect cognitive and physical phenotypes. American Journal of Human Genetics, 64: $118-125$.

Tauroza, S., \& Allison, D. (1990). Speech rates in British English. Applied Linguistics, 11, 90-105. doi: 10.1093/applin/11.1.90.

Thomas, K. M., \& Nelson, C. A. (2001). Serial reaction time learning in preschool- and school-age children. Journal of Experimental Child Psychology, 79, 364-387. doi: doi:10.1006/jecp.2000.2613.

Thomas, S. C. M., Grant, J., Barham, Z., Dsodl, M., Laing, E., Lakusta, L., ...KarmloffSmith, A. (2001). Past tense formation in Williams syndrome. Language and Cognitive Processes, 16 (2/3), 143-176. doi: 10.1080/01690960042000021

Thomas, S.C.M., Purser, H. R., \& Van Herwegen, J. (2012). Cognition: The developmental trajectory approach. In E. K. Farran \& A. Karmiloff-Smith (Eds.), Neurodevelopmental diosrders across the lifespan: A neuroconstructivist approach (pp. 13-35). Oxford: Oxford University Press.

Trehub, S. E. (2003). The developmental origins of music. Nature Neuroscience, 6, 669-673

Vinter, A., \& Perruchet, P. (2000). Implicit learning in children is not related to age: Evidence from drawing behavior. Child Development, 71(5), 1223-1240. doi: $10.1111 / 1467-8624.00225$.

Visser, I., Raijmakers, M. E. J., \& Pothos, E. M. (2009). Individual strategies in artificial grammar learning. American Journal of Psychology, 122(3), 293-307. doi: 27784404.

Wang, P.P., Doherty, S., Rourke, S.B., \& Bellugi, U. (1995). Unique profile of visuoperceptual skills in a genetic syndrome. Brain and Cognition, 29(1), 54-65. doi: 10.1006/brcg.1995.1267.

Wang, L., Mottron, L., Peng, D., Berthiaume, C., \& Dawson, M. (2007). Local bias and local-to-global interference without global deficit: A robust finding in autism under 
various conditions of attention, exposure time, and visual angle. Cognitive Neuropsychology, 24(5), 550-574. doi:10.1080/13546800701417096

Wexler, K., \& Culicover, P. W. (1980). Formal principles of language acquisition. Cambridge, MA: MIT Press.

Young, A. W., Hellawell, D., \& Hay, D. C. (1987). Configurational information in face perception. Perception, 16, 747-759.doi: 10.1068/p160747.

Ypsilanti, A., Grouios, G., Alevriadou, A., \& Tsapkini, K. (2005). Expressive and receptive vocabulary in children with Williams and Down syndromes. Journal of Intellectual Disability Research, 49(5), 353-364. doi: 10.1111/j.1365-2788.2005.00654.x

Zimmerer, V. C., Cowell, P. E., \& Varley, R. A. (2011). Individual behavior in learning of an artificial grammar. Memory \& Cognition, 39(3), 491-501. doi: 10.3758/s13421-0100039-y.

Zimmerer, V. C., Cowell, P. E., \& Varley, R. A. (2014). Artificial grammar learning in individuals with severe aphasia. Neuropsychologia, 53, 25-38. doi:10.1016/j.neuropsychologia.2013.10.014

Zimmerer, V. C., \& Varley, R. A. (2015). A case of “order insensitivity"? Natural and artificial language processing in a man with primary progressive aphasia. Cortex, 69 , 212-9. doi:10.1016/j.cortex.2015.05.006 


\section{APPENDIX}

Phrases used in judgment task (experimental trial)

Familiar Grammatical

$\mathrm{A}, \mathrm{C} \quad$ ranos banton

$\mathrm{A}, \mathrm{C} \quad$ lanel pidur

$\mathrm{A}, \mathrm{B}, \mathrm{C}$ rana subi pafil

$\mathrm{A}, \mathrm{B}, \mathrm{C}$ lannut seto pidur

$\mathrm{A}, \mathrm{B}, \mathrm{C}$ ranos seto budoc

$\mathrm{A}, \mathrm{B}, \mathrm{C}$ rana seto banton

Unfamiliar Grammatical

$\mathrm{A}, \mathrm{C} \quad$ lanel banton

$\mathrm{A}, \mathrm{C} \quad$ raret pidur

A, B, C lannut subi belsop

$\mathrm{A}, \mathrm{B}, \mathrm{C}$ ranos surug budoc

$\underline{\text { Ungrammatical }}$

$\mathrm{C}, \mathrm{A}, \mathrm{A}$ pafil rana rana

A, A, C lannut lannut belsop

A, B, B lanel subi subi

$\mathrm{B}, \mathrm{B} \quad$ seto surug

C, C, C pafil budoc pidur

A, A, A lanel ranos raret

A, B lanel seno

C, B belsop seno

A, C, B pidur lannut surug

$\mathrm{C}, \mathrm{B}, \mathrm{A}$ banton seto ranos 